\title{
Bariatric Surgery Impact on Cardiovascular Risk Factors: Is Age a Factor to Consider?
}

\author{
Fernando Mendonça ${ }^{a, b}$ Maria Manuel Silva ${ }^{a, b}$ Daniela Salazara, b \\ Maria João Ferreira ${ }^{a, b}$ Jorge Pedro ${ }^{a, b}$ Vanessa Guerreiro ${ }^{a, b}$ Sara Viana ${ }^{c}$ \\ Joao Sérgio Neves ${ }^{a, b, d}$ Sandra Belo ${ }^{a, b, d} \quad$ Ana Varela $a, b, d \quad$ Paula Freitas ${ }^{a, b, d}$ \\ Davide Carvalho a, b, d CRIO Group ${ }^{e}$
}

a Department of Endocrinology, Diabetes and Metabolism, Centro Hospitalar Universitário de S. João, Porto, Portugal; ${ }^{b}$ Faculty of Medicine, Universidade do Porto, Porto, Portugal; ' Unidade Local de Saúde do Norte Alentejano EPE, Évora, Portugal; ' Instituto de Investigação e Inovação em Saúde da Universidade do Porto, Porto,

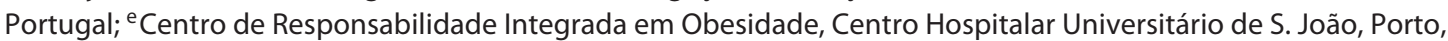
Portugal

\section{Keywords}

Bariatric surgery $\cdot$ Age $\cdot$ Outcomes $\cdot$ Weight loss $\cdot$ Diabetes mellitus · Dyslipidemia · Hypertension

\begin{abstract}
Introduction: Despite the abundance of data addressing the influence of patient's age on surgery-related complications, its impact on cardiometabolic outcomes following bariatric surgery has been overlooked. Methods: Retrospective unicentric study of 1,728 obese patients who underwent bariatric surgery between January 2010 and June 2015. Patients were divided in 3 age groups, according to their age at surgery: $<40(n=751), 40-59(n=879)$, and $\geq 60$ years $(n=98)$. Parameters with cardiometabolic impact, such as body anthropometric measures, lipid profile, and glycemic status, before and 24 months after surgery, were compared between these groups. A multiple linear regression was performed, adjusting differences between groups for sex, surgery type, and body mass index variation. Results: The group $<40$ years presented more weight loss $(-35.4 \pm 9.0 \mathrm{~kg}, p<$
\end{abstract}

(C) 2020 The Author(s)

Published by S. Karger AG, Basel

This is an Open Access article licensed under the Creative Commons Attribution-NonCommercial-4.0 International License (CC BY-NC) (http://www.karger.com/Services/OpenAccessLicense), applicable to the online version of the article only. Usage and distribution for commercial purposes requires written permission.
$0.001)$, greater BMI reduction $\left(-15.8 \pm 6.1 \mathrm{~kg} / \mathrm{m}^{2}, p<0.001\right)$, and larger changes in waist $(-34 \pm 13.8 \mathrm{~cm}, p<0.001)$ and hip circumferences $(-28.7 \pm 11.9 \mathrm{~cm}, p<0.05)$. The group of $\geq 60$ years presented the heaviest reduction in fasting glucose $(-17.7 \pm 32.8 \mathrm{mg} / \mathrm{dL}, p<0.001)$ and $\mathrm{HbA} 1 \mathrm{c}(0.7 \pm 1.0, p<$ 0.001 ), and also had a tendency to have the biggest changes in systolic blood pressure $(-14.7 \pm 18.7 \mathrm{~mm} \mathrm{Hg}, p=0.071)$. Conclusion: Patients with $\geq 60$ years benefit the most from bariatric surgery regarding cardiometabolic parameters, presenting heavier reductions in fasting glucose, as well as $\mathrm{HbA} 1 \mathrm{c}$ and a tendency towards a higher decrease in systolic blood pressure. No clinically significant differences in lipid profile were observed between groups.

(C) 2020 The Author(s)

Published by S. Karger AG, Basel

\section{Introduction}

Obesity is a major health problem worldwide. The World Health Organization estimated in 2016 that 650 million adults were affected by this disease, with a preva- 
lence that has almost tripled since 1975 [1]. Bariatric surgery is currently the intervention with the greatest impact in achieving weight loss among the severely obese, as it is cost-effective and leads to significant reductions in morbidity and mortality, while improving psychosocial functioning and quality of life [2-4]. Choosing bariatric surgery as an obesity treatment among older adults is still controversial. Despite the general perception of an increased risk for perioperative and postoperative complications, the available data did not reach consensus, with some papers supporting this idea [5-7], whilst others state that patient's age may not be an essential factor to consider for this issue $[8,9]$. As a result, surgical decisions in this specific setting are still made on a case-by-case basis across the world, with careful evaluation of risks and benefits. A reasonable amount of data exists regarding the impact of patient age on bariatric surgery post-operative outcomes $[6,8-11]$. Despite this fact, there is a shortage of data addressing the role of age at the moment of surgery on anthropometric measures, lipid profile, glycemic status, and blood pressure. Considering that these parameters play a pivotal role for cardiometabolic health, as they are associated indirectly with patient morbidity and mortality [12-14], it is important to understand the impact that age has on the variation of these factors after bariatric surgery. This could ultimately be another player that needs to be considered by the clinician during the evaluation of surgical risks and benefits, especially in the case of older patients.

\section{Methods}

We conducted a retrospective observational study with 1,728 obese patients who underwent bariatric surgery (either Rouxen-Y gastric bypass [RYGB] or sleeve gastrectomy [SG]) at our hospital between January 2010 and June 2015. All patients were consecutively selected and followed by the Multidisciplinary Group for Surgical Management of Obesity, after having met the standard eligibility criteria for bariatric surgery, which are: (1) body mass index $(\mathrm{BMI}) \geq 35 \mathrm{~kg} / \mathrm{m}^{2}$ with 2 or more preoperative comorbidities (diabetes mellitus type 2, dyslipidemia, hypertension, obstructive sleep apnea syndrome, among others) or BMI $\geq 40 \mathrm{~kg} / \mathrm{m}^{2}$; (2) age between 18 and 65 years included; (3) nonsatisfactory weight loss after, at least, 1 year under all the appropriate non-surgical measures; (4) obesity which is non-secondary to classical endocrine disease; (5) ability to understand the surgical procedure and to adhere to a long-term follow-up plan; and (6) absence of non-stabilized psychiatric disturbances or alcohol/narcotic abuse.

We divided the patients into 3 major groups, considering the age at the time of surgery ( $<40$ years, $\geq 40$ and $<60$ years, $\geq 60$ years). These groups were compared at baseline and 24 months after surgery for parameters with putative cardiometabolic impact, such as sex, weight, body mass index (BMI), waist circumference (WC), hip circumference (HC), LDL cholesterol (LDL), HDL cholesterol (HDL), triglycerides (TG), glycemic status (fasting plasma glucose levels and hemoglobin A1C - HbA1c), systolic blood pressure (SBP), and diastolic blood pressure (DBP).

To fully understand the impact of patient's age on these parameters, we carried out a comparison between groups regarding their variation between baseline and 24 months after surgery, and the same for the proportion of patients with diabetes mellitus and hypertension achieving remission. In this specific analysis (Table 1), patients presenting missing data at 24 months after surgery were excluded.

The proportion of patients with dyslipidemia, hypertension, and diabetes mellitus was also assessed at baseline and 24 months after surgery and was compared between groups. Hypertension was defined as SBP $\geq 140 \mathrm{~mm} \mathrm{Hg}, \mathrm{DPB} \geq 90 \mathrm{~mm} \mathrm{Hg}$ or a patient taking anti-hypertensive medication; diabetes mellitus (DM) was defined as fasting plasma glucose $\geq 126 \mathrm{mg} / \mathrm{dL}, \mathrm{HbA} 1 \mathrm{c} \geq 6.5 \%$, 2 -h post-load plasmatic glucose $\geq 200 \mathrm{mg} / \mathrm{dL}$ during an oral glucose tolerance test (OGTT) or a patient taking hypoglycemic drug; dyslipidemia was defined as $\mathrm{LDL} \geq 160 \mathrm{mg} / \mathrm{dL}, \mathrm{HDL}<40 \mathrm{mg} / \mathrm{dL}$, triglyceride $\geq 200 \mathrm{mg} / \mathrm{dL}$ or a patient taking anti-dyslipidemic medication. Remission, for a given pathology, was considered when a previously diagnosed patient did not meet any of the above-mentioned diagnostic criteria 24 months after surgery.

\section{Statistical Analysis}

Continuous variables with normal distribution were presented as means and SD and were compared using one-way ANOVA. Continuous variables with non-normal distribution were described as medians and interquartile range. The differences between the 3 age groups were compared using the Kruskal-Wallis test. Categorical variables were expressed as percentages and were compared by using a $\chi^{2}$ test.

The differences between groups that achieved statistical significance in the univariate analysis regarding the variation of parameters between baseline and 24 months were included in linear regressions models, in order to adjust for possible confounding variables (sex, surgery type - SG vs. RYGB, and BMI variation). Reported $p$ values are 2 -tailed and $p \leq 0.05$ was considered statistically significant. Analyses were performed with the use of SPSS Statistics $25^{\circledR}$ software.

\section{Results}

\section{Comparison between Groups at Baseline and 24} Months after Surgery

A total of 1,728 consecutive obese patients who underwent bariatric surgery (SG or RYGB) from January 2010 to June 2015 were studied, and were divided into 3 major groups, according to patient age at the time of surgery. Group 1 was composed of 751 patients younger than 40 years, group 2 included 879 patients aged between 40 and 59 years, and group 3 included 98 patients aged 60 year or more. 
Table 1. Comparison of age groups regarding parameter variation between before and 2 years after surgery

\begin{tabular}{|c|c|c|c|c|c|}
\hline $\begin{array}{l}\text { Parameter variation } \\
\text { (- baseline value }-2 \\
\text { year value) }\end{array}$ & $\begin{array}{l}\text { Group } 1 \\
<40 \text { years } \\
(n=521)\end{array}$ & $\begin{array}{l}\text { Group } 2 \\
\geq 40 \text { and }<60 \text { years } \\
(n=657)\end{array}$ & $\begin{array}{l}\text { Group } 3 \\
\geq 60 \text { years } \\
(n=72)\end{array}$ & $p$ value & $\begin{array}{l}\text { Adjusted } \\
p \text { value }^{*}\end{array}$ \\
\hline $\mathrm{BMI}, \mathrm{kg} / \mathrm{m}^{2}$ & $-15.8 \pm 6.1$ & $-14.3 \pm 5.1$ & $-13.3 \pm 5.3$ & $<0.001$ & $<0.001$ \\
\hline Waist circumference, $\mathrm{cm}$ & $-34.0 \pm 13.8$ & $-29.1 \pm 12.1$ & $-28.0 \pm 13.0$ & $<0.001$ & $<0.001$ \\
\hline Hip circumference, $\mathrm{cm}$ & $-28.7 \pm 11.9$ & $-26.1 \pm 11.1$ & $-23.3 \pm 11.0$ & 0.021 & 0.049 \\
\hline $\mathrm{LDL}, \mathrm{mg} / \mathrm{dL}$ & $-17.5 \pm 26.9$ & $-21.4 \pm 35.6$ & $-12.3 \pm 33.2$ & 0.097 & 0.315 \\
\hline $\mathrm{HDL}, \mathrm{mg} / \mathrm{dL}$ & $+12.0 \pm 11.8$ & $+9.0 \pm 12.0$ & $+10.0 \pm 13.5$ & 0.001 & 0.062 \\
\hline $\mathrm{TG}, \mathrm{mg} / \mathrm{dL}$ & $-36.0 \pm 58.3$ & $-40.0 \pm 58.0$ & $-35.0 \pm 59.0$ & 0.571 & 0.482 \\
\hline Glucose, mg/dL & $-6.0 \pm 16.0$ & $-13.0 \pm 22.0$ & $-17.7 \pm 32.8$ & $<0.001$ & $<0.001$ \\
\hline $\mathrm{HbA1c}, \%$ & $-0.2 \pm 0.5$ & $-0.4 \pm 0.7$ & $-0.7 \pm 1.0$ & $<0.001$ & $<0.001$ \\
\hline HOMA-IR & $-2.9 \pm 3.2$ & $-2.5 \pm 3.5$ & $-7.1 \pm 5.8$ & 0.075 & 0.677 \\
\hline
\end{tabular}

BMI, body mass index; LDL, Low density lipoprotein; HDL, high density lipoprotein; TG, triglycerides; HbA1C, Hemoglobin A1C; HOMA-IR, insulin resistance determined by homeostatic model assessment; SBP, systolic blood pressure; DBP, diastolic blood pressure. * Variables adjusted to sex, surgery type and BMI variation (except BMI variation and weight variation that were only adjusted to sex and surgery type). ${ }^{1}$ Diabetes remission was calculated considering the proportion of diabetic patients at baseline that achieved remission 2 years after surgery. At baseline, group 1 had 99 diabetic patients, group 2 had 220 and group 3 had 37 diabetic patients. ${ }^{2}$ Hypertension remission was calculated considering the proportion of diabetic patients at baseline that achieved remission 2 years after surgery. At baseline, group 1 had 113 hypertensive patients, group 2 had 376 and group 3 had 58 hypertensive patients. ${ }^{1,2}$ It is relevant to point out that the number of diabetic and hypertensive patients at baseline is higher but some of these patients presented missings regarding diabetes and hypertension status at 2 years and, for this reason, were excluded of this calculation.

At baseline, group 1 had the heaviest patients (120.4 \pm $19.3 \mathrm{~kg})$, which also presented the lowest proportion of diabetic (22.1\%), hypertensive (57.3\%), and dyslipidemic patients (39.7\%). Group 3 presented the opposite results, with the obese patients having less weight $(111.2 \pm 15.7$ $\mathrm{kg}$ ) and the highest proportion of individuals with diabetes (68.4\%), hypertension (95.9\%), and dyslipidemia $(89.2 \%)$. All these differences were statistically significant $(p<0.001)$. On the other hand, there was no difference at baseline BMI between groups $(p=0.191)$. Focusing on the baseline lipid profile, group 2 presented the highest levels of LDL cholesterol $(127.1 \pm 33.6 \mathrm{mg} / \mathrm{dL}, p=0.042)$ and $\mathrm{TG}(127.0 \pm 33.6 \mathrm{mg} / \mathrm{dL}, p<0.001)$. No clinically significant differences between groups were found regarding HDL cholesterol levels. The glycemic status also presented divergent results at baseline: Group 1 had the lowest levels of fasting glucose $(88.0 \pm 17.0 \mathrm{mg} / \mathrm{dL})$ and HA1c $(5.4 \pm 0.8 \%)$, while group 3 presented the highest values of fasting plasma glucose levels $(106.0 \pm 42.0 \mathrm{mg} / \mathrm{dL})$ and $\mathrm{HbA1C}(6.1 \pm 1.2 \%)$, these differences being statistically significative $(p<0.001)$. Insulin resistance determined by homeostatic model assessment (HOMA-IR) was also higher among the older patients at baseline $(7.4 \pm 6.9, p=$ 0.036 ). When we addressed the blood pressure profile at baseline, we found differences in the SBP, with higher blood pressures in group $3(140.0 \pm 18.9 \mathrm{~mm} \mathrm{Hg})$ and lower pressures in group $1(129.7 \pm 16.2 \mathrm{~mm} \mathrm{Hg}, p<$ 0.001 ), although there were no clinically significant differences regarding DBP between groups.

When we evaluated the same parameters 24 months after surgery, we found slightly different results. There was no difference between groups regarding the weight of the subjects $(p=0.843)$. In contrast with the baseline data, group 3 presented the highest BMI $\left(31.3 \pm 4.7 \mathrm{~kg} / \mathrm{m}^{2}\right)$, while group 1 had the lowest BMI $\left(28.5 \pm 4.6 \mathrm{~kg} / \mathrm{m}^{2}, p<\right.$ $0.001)$. The same occurred with WC $(101.3 \pm 10.5 \mathrm{~cm}$ vs. $89.1 \pm 13.1 \mathrm{~cm}, p<0.001)$ and with the proportion of diabetic ( 36.8 vs. $3.0 \%, p<0.001$ ), hypertensive ( 80.0 vs. $19 \%$, $p<0.001$ ), and dyslipidemic patients (59.6 vs. $5.4 \%, p<$ 0.001 ). When we focused on lipid profile, group 3 presented the highest levels of TG $(93.5 \pm 43.0 \mathrm{mg} / \mathrm{dL}, p<$ 0.001 ), and no clinically significant differences between 
Table 2. Comparison between age groups regarding various cardiometabolic parameters at baseline and 2 years after surgery

\begin{tabular}{|c|c|c|c|c|c|c|c|c|}
\hline & \multicolumn{2}{|c|}{$\begin{array}{l}\text { Group } 1 \\
<40 \text { years }(n=751) \\
(n=521)\end{array}$} & \multicolumn{2}{|c|}{$\begin{array}{l}\text { Group } 2 \\
\geq 40 \text { and }<60 \text { years }(n=879) \\
(n=657)\end{array}$} & \multicolumn{2}{|c|}{$\begin{array}{l}\text { Group } 3 \\
\geq 60 \text { years }(n=98) \\
(n=72)\end{array}$} & \multirow{2}{*}{$\begin{array}{l}p \text { value } \\
\text { baseline }\end{array}$} & \multirow{2}{*}{$\begin{array}{l}p \text { value } \\
2 \text { years }\end{array}$} \\
\hline & baseline & 2 years & baseline & 2 years & baseline & 2 years & & \\
\hline Female, \% & $84.7(636)$ & $84.8(442)$ & $85.2(749)$ & $85.8(563)$ & $81.6(80)$ & $83.4(60)$ & $<0.001$ & $<0.001$ \\
\hline Age, years & $32.2 \pm 22.0$ & $35.0 \pm 8.0$ & $48.3 \pm 19.0$ & $50.0 \pm 10.0$ & $62.5 \pm 7.0$ & $64.0 \pm 3.0$ & $<0.001$ & $<0.001$ \\
\hline Surgery & & & & & & & $<0.001$ & $<0.001$ \\
\hline SG, \% & $33.6(252)$ & $28.8(150)$ & 32.5 (593) & 29.7 (205) & $41.8(41)$ & $52.8(38)$ & & \\
\hline RYGB, \% & $66.4(499)$ & $71.2(371)$ & $67.5(286)$ & $70.3(462)$ & $58.2(57)$ & $47.2(34)$ & & \\
\hline Weight, kg & $120.4 \pm 19.3$ & $76.8 \pm 14.2$ & $113.8 \pm 18.2$ & $77.1 \pm 14.8$ & $111.2 \pm 15.7$ & $77.8 \pm 13.6$ & $<0.001$ & 0.843 \\
\hline BMI, $\mathrm{kg} / \mathrm{m}^{2}$ & $44.2 \pm 5.6$ & $28.5 \pm 4.6$ & $43.8 \pm 5.8$ & $29.7 \pm 4.8$ & $44.4 \pm 6.0$ & $31.3 \pm 4.7$ & 0.191 & $<0.001$ \\
\hline WC, $\mathrm{cm}$ & $123.6 \pm 13.8$ & $89.1 \pm 13.1$ & $122.3 \pm 12.7$ & $93.8 \pm 12.9$ & $127.6 \pm 13.7$ & $101.3 \pm 10.5$ & 0.006 & $<0.001$ \\
\hline $\mathrm{HC}, \mathrm{cm}$ & $134.0 \pm 11.2$ & $104.2 \pm 10.0$ & $131.2 \pm 11.1$ & $106.0 \pm 10.5$ & $133.3 \pm 12.7$ & $111.7 \pm 10.0$ & $<0.001$ & $<0.001$ \\
\hline DM, \% & 22.1 & 3.1 & 43.5 & 15.2 & 68.4 & 37.5 & $<0.001$ & $<0.001$ \\
\hline HTN, \% & 57.3 & 19.0 & 80.0 & 57.3 & 95.9 & 80.0 & $<0.001$ & $<0.001$ \\
\hline Dyslip, \% & 39.7 & 5.4 & 54.2 & 21.2 & 89.2 & 59.6 & $<0.001$ & $<0.001$ \\
\hline $\mathrm{LDL}, \mathrm{mg} / \mathrm{dL}$ & $118.5 \pm 30.0$ & $101.0 \pm 23.6$ & $127.1 \pm 33.6$ & $105.1 \pm 28.8$ & $116.3 \pm 36.3$ & $104.0 \pm 30.0$ & 0.042 & 0.246 \\
\hline $\mathrm{HDL}, \mathrm{mg} / \mathrm{dL}$ & $48.7 \pm 11.9$ & $61.8 \pm 12.0$ & $50.2 \pm 11.4$ & $60.4 \pm 11.5$ & $48.2 \pm 11.8$ & $57.9 \pm 13.7$ & $<0.001$ & 0.026 \\
\hline $\mathrm{TG}, \mathrm{mg} / \mathrm{dL}$ & $118.4 \pm 30.0$ & $76.0 \pm 41.0$ & $127.0 \pm 33.6$ & $83.0 \pm 41.0$ & $116.3 \pm 36.7$ & $93.5 \pm 43.0$ & $<0.001$ & $<0.001$ \\
\hline Glucose, $\mathrm{mg} / \mathrm{dL}$ & $88.0 \pm 17.0$ & $82.0 \pm 10.0$ & $99.0 \pm 24.0$ & $85.0 \pm 10.0$ & $106.0 \pm 42.0$ & $93.0 \pm 21.0$ & $<0.001$ & $<0.001$ \\
\hline $\mathrm{HbAlc}, \%$ & $5.4 \pm 0.8$ & $5.2 \pm 0.5$ & $5.8 \pm 0.8$ & $5.3 \pm 0.5$ & $6.1 \pm 1.2$ & $5.5 \pm 0.7$ & $<0.001$ & $<0.001$ \\
\hline HOMA-IR & $4.2 \pm 3.56$ & $1.3 \pm 0.9$ & $3.8 \pm 3.8$ & $1.2 \pm 0.8$ & $7.4 \pm 6.9$ & $1.5 \pm 1.1$ & 0.036 & 0.113 \\
\hline SBP, mm Hg & $129.7 \pm 16.2$ & $119.0 \pm 13.9$ & $136.0 \pm 17.4$ & $123.5 \pm 17.3$ & $140.0 \pm 18.9$ & $128.4 \pm 14.0$ & $<0.001$ & $<0.001$ \\
\hline DBP, $\mathrm{mm} \mathrm{Hg}$ & $82.1 \pm 11.0$ & $72.0 \pm 15.0$ & $84.1 \pm 11.1$ & $76.0 \pm 10.0$ & $83.8 \pm 9.9$ & $77.5 \pm 10.0$ & $<0.001$ & 0.073 \\
\hline
\end{tabular}

BMI, body mass index; WC, waist circumference; HC, hip circumference; DM, diabetes mellitus; HTN, hypertension; Dyslip, dyslipidemia; LDL, low-density lipoprotein; HDL, high-density lipoprotein; TG, triglycerides; HbA1C, hemoglobin A1C; HOMA-IR, insulin resistance determined by homeostatic model assessment; SBP, systolic blood pressure; DBP, diastolic blood pressure.

groups were found on LDL and HDL cholesterol plasmatic levels. In addition, there was an increase of fasting plasma glucose levels $(82.0 \pm 10.0$ vs. $85.0 \pm 10.0$ vs. 93.0 $\pm 21.0 \mathrm{mg} / \mathrm{dL}, p<0.001)$ and $\mathrm{HbAlc}(5.2 \pm 0.5$ vs. $5.3 \pm$ 0.5 vs. $5.5 \pm 0.7, p<0.001)$ with ageing. There were no statistically significant differences between groups regarding the HOMA-IR. Finally, patients from group 3 had the highest SBP levels, with the opposite occurring among those from group $1(128.4 \pm 14.0$ vs. $119.0 \pm 13.9$ $\mathrm{mm} \mathrm{Hg}, p<0.001)$. Although no statistically significant differences between groups were found on DBP (72.0 \pm 15.0 vs. $76.0 \pm 10.0$ vs. $77.5 \pm 10.0 \mathrm{~mm} \mathrm{Hg}, p=0.073)$, there seems to be a tendency of higher SBP in older patients, 24 months after bariatric surgery (Table 2).

\section{Comparison of the Variation of Parameters between Groups}

In a second phase, the differences between measurements at baseline and 24 months after surgery, only on those patients without missings on any of these 2 time points, were analyzed. The oldest group (group 3) presented less weight loss $(-35.4 \pm 9.0$ vs. $-32.2 \pm 8.9$ vs. -29.3 $\pm 9.2 \mathrm{Kg}, p<0.001)$ and smaller BMI variation $(-15.78 \pm$ 6.1 vs. $-14.34 \pm 5.1$ vs. $\left.-13.29 \pm 5.3 \mathrm{~kg} / \mathrm{m}^{2}, p<0.001\right)$. The same occurred with waist $(-28.0 \pm 13.0 \mathrm{~cm}, p<0.001)$ and hip circumference $(-23.3 \pm 11.0 \mathrm{~cm}, p=0.049)$. Interestingly, despite having a smaller variation in the anthropometric measures, group 3 presented the most prominent differences in fasting plasma glucose levels $(-17.7 \pm 32.8$ $\mathrm{mg} / \mathrm{dL}, p<0.001)$ and HA1c $(-0.7 \pm 1.0 \%, p<0.001)$. In addition, there seems to be a tendency among this group to have higher reductions in SBP $(-14.7 \pm 18.7 \mathrm{~mm} \mathrm{Hg}$, $p=0.071$.

The proportion of diabetic patients achieving diabetes remission was higher in the group with younger patients $(89.0 \%)$ and lower in the oldest group (45.9\%), with the same occurring with the hypertensive patients (65.5 vs. $15.2 \%)$. No differences were found between groups regarding the variation of DBP. Despite group 3 having a smaller reduction of LDL cholesterol $(-12.3 \pm 33.2 \mathrm{mg} / \mathrm{dL}$, $p=0.315)$ and TG $(-35.0 \pm 59.0 \mathrm{mg} / \mathrm{dL}, p=0.482)$, there were no statistically significant differences between groups (Table 1). All the groups presented an increase in HDL cholesterol levels after surgery, and a decrease in all other lipid parameters. The influence of sex and surgery type on the variation of all these parameters according to age group is presented in the online supplementary materiall and2 (seewww.karger.com/doi/10.1159/000511737).

\section{Discussion}

Our study is in line with previous data, which confirms a more prominent effect of bariatric surgery on weight loss among younger individuals $[15,16]$, being the ones with the greatest changes in the other anthropometric measures (BMI, HC and WC). Conversely, the opposite occurs with the group containing the older patients 
(group 3). This could be explained by their diminished metabolic rate, an increased prevalence of sarcopenia, and a longer time suffering from comorbidities that influence their physical condition [17]. Despite this fact, our research shows that patients older than 60 years at the time of surgery are those with the greatest cardiometabolic benefits, presenting the highest reductions of fasting glucose and HbA1c ( $p$ adjusted $<0.001$ ) and also a tendency to have a greater reduction in the SBP ( $p$ adjusted $=0.071$ ). These findings were independent of patient's sex, type of surgery, and BMI variation. In addition, the oldest patients have also a relevant proportion of hypertension and diabetes remission 24 months after surgery (45.9 and 15.2\%, respectively). Previous data regarding cardiometabolic risk effects of bariatric surgery among the elderly found similar benefic results on diabetes, hypertension and dyslipidemia remission [18]. Despite having the smallest improvement of glycemic and tensional parameters, the youngest group presented the highest rates of diabetes mellitus and hypertension remission. This occurred probably because they also had the best glycemic and tensional profile at baseline of all groups (Table 2), making it easier to achieve remission.

These results should be considered when weighing the pros and cons of bariatric surgery in older patients. Despite the expected increase of surgical risk, the pronounced positive effect on parameters with cardiometabolic impact may be worth the risk in selected cases with no major contraindications for surgery.

Further research is needed in order to shed a light on the cost-effectiveness of bariatric surgery in elderly individuals (even those older than 65 years) and also to obtain more information regarding the impact of age on the parameters presented with cardiometabolic impact. The authors believe that not only will the surgery option decrease the costs related with diabetes and hypertension management during follow-up, but it will also lead to an increase in life expectancy and well-being among these patients. These are crucial factors which are making other researchers start to question the legitimacy of setting 65 years as the maximum age for performing bariatric surgery [19]. Data regarding the impact of bariatric surgery on cardiometabolic risk among elderly individuals found a benefic effect on weight loss, glucose and lipid profile. In addition, it led to a significant decrease of the prevalence of hypertension, diabetes mellitus and dyslipidemia, being an effective procedure in this population [18].

Some researchers believe that in selected cases, surgery might even be an option in the future for patients older than 75 years, considering that the procedure remains safe and effective (despite the higher risk of patient-associated comorbidities) [20].

The main strength of this retrospective study is the high number of subjects studied, who were consecutively selected in just one hospital center. In addition, this is one of the first studies, to our knowledge, to focus on the impact of patient age on glycemic status, lipidic profile, and blood pressure, which accordingly adds new data to the benefits of bariatric surgery in individuals older than 60 years. Despite these facts, we are aware that the majority of subjects in our study were women (more than 80\%) and, for this reason, the $p$ value regarding the differences of parameter variation between groups (Table 1) was also adjusted to sex.

Regarding the limitations of the study, it is relevant to point out that this is a retrospective study with consecutive patient selection. This led to a disproportion between group sizes (group 1: $n=751$, group 2: $n=879$; group 3: $n=98$ ). In addition, we would have liked to address specifically the impact of bariatric surgery on patients $\geq 65$ years, but our tiny population would limit the validity of the conclusions ( $n=18$ patients, 4 submitted to RYGB and 14 submitted to SG). We also did not question our patients about their exercise capability/adherence, neither the presence of pathologies preventing them from exercising (such as osteoarthritis), nor diet habits after surgery, which are aspects that should be considered when interpreting these results. In this article, we also do not present the complication rate of each surgical procedure, a factor that should be considered before choosing the type of surgery.

\section{Acknowledgements}

We would like to thank the valuable contribution of the following members of the CRIO Group: John Preto, Eduardo Lima da Costa, Hugo Sousa, André Pinho, Eva Lau, Selma Souto, Carla Galego, Flora Correia, Cidália Gil, Diva Melim, Eduardo Pinto, Marco Silva, Cristina Martins, Luis Miguel Pereira, Inês Magalhães, Isabel Brandão, Sertório Manuel Andrade, Patrícia Nunes.

\section{Statement of Ethics}

All procedures performed in this study involving human participants were in accordance with the ethical standards of the institutional and/or national research committee and with the 1964 Helsinki Declaration and its later amendments or comparable ethical standards. All patients have provided written consent, and the study was approved by the Ethics Committee for Health of the Centro Hospitalar de São João (CHSJ)/Faculdade de Medicina da Universidade do Porto (FMUP).
Mendonça et al. 


\section{Conflict of Interest Statement}

The authors declare that they have no conflicts of interest.

\section{Funding Sources}

No funding to declare.

\section{References}

1 World Health Organization. Obesity and overweight fact sheet. [cited March 24, 2018]; Available from: https://www.who.int/news$\mathrm{room} /$ fact-sheets/detail/obesity-and-overweight.

2 Picot J, Jones J, Colquitt JL, Gospodarevskaya E, Loveman E, Baxter L, et al. The clinical effectiveness and cost-effectiveness of bariatric (weight loss) surgery for obesity: a systematic review and economic evaluation. Health Technol Assess. 2009 Sep;13(41):1-190.

3 Gloy VL, Briel M, Bhatt DL, Kashyap SR, Schauer PR, Mingrone G, et al. Bariatric surgery versus non-surgical treatment for obesity: a systematic review and meta-analysis of randomised controlled trials. BMJ. 2013 Oct; 347:f5934.

4 Kubik JF, Gill RS, Laffin M, Karmali S. The impact of bariatric surgery on psychological health. J Obes. 2013;2013:837989.

5 Lin HS, Watts JN, Peel NM, Hubbard RE. Frailty and post-operative outcomes in older surgical patients: a systematic review. BMC Geriatr. 2016 Aug;16(1):157-157.

6 Susmallian S, Barnea R, Weiss Y, Raziel A. Outcome of bariatric surgery in older patients. Surg Obes Relat Dis. 2018 Nov; 14(11): 1705-13.

7 Livingston EH, Langert J. The impact of age and Medicare status on bariatric surgical outcomes. Arch Surg. 2006 Nov;141(11):111520.
8 Gonzalez-Heredia R, Patel N, Sanchez-Johnsen L, Masrur M, Murphey M, Chen J, et al. Does Age Influence Bariatric Surgery Outcomes? Bariatr Surg Pract Patient Care. 2015 Jun;10(2):74-8.

9 Major P, Wysocki M, Janik M, Stefura T, Walędziak M, Pędziwiatr M, et al. Impact of age on postoperative outcomes in bariatric surgery. Acta Chir Belg. 2018 Oct;118(5): $307-14$.

10 Davidson LE, Adams TD, Kim J, Jones JL, Hashibe M, Taylor D, et al. Association of Patient Age at Gastric Bypass Surgery With Long-term All-Cause and Cause-Specific Mortality. JAMA Surg. 2016 Jul;151(7):6317.

11 Sanni A, Perez S, Medbery R, Urrego HD, McCready C, Toro JP, et al. Postoperative complications in bariatric surgery using age and BMI stratification: a study using ACS-NSQIP data. Surg Endosc. 2014 Dec;28(12):3302-9.

12 Orozco-Beltran D, Gil-Guillen VF, Redon J, Martin-Moreno JM, Pallares-Carratala V, Navarro-Perez J, et al.; ESCARVAL Study Group. Lipid profile, cardiovascular disease and mortality in a Mediterranean high-risk population: the ESCARVAL-RISK study. PLoS One. 2017 Oct;12(10):e0186196.

13 Yi SW, Park S, Lee YH, Park HJ, Balkau B, Yi JJ. Association between fasting glucose and all-cause mortality according to sex and age: a prospective cohort study. Sci Rep. 2017 Aug; 7(1):8194-8194.
14 van Trijp MJ, Grobbee DE, Peeters PH, van Der Schouw YT, Bots ML. Average blood pressure and cardiovascular disease-related mortality in middle-aged women. Am J Hypertens. $2005 \mathrm{Feb}$;18(2 Pt 1):197-201.

15 Contreras JE, Santander C, Court I, Bravo J. Correlation between age and weight loss after bariatric surgery. Obes Surg. 2013 Aug;23(8): 1286-9.

16 Scozzari G, Passera R, Benvenga R, Toppino $\mathrm{M}$, Morino $\mathrm{M}$. Age as a long-term prognostic factor in bariatric surgery. Ann Surg. 2012 Nov;256(5):724-8.

17 Giordano S, Victorzon M. Bariatric surgery in elderly patients: a systematic review. Clin Interv Aging. 2015 Oct; 10:1627-35.

18 Batsis JA, Miranda WR, Prasad C, CollazoClavell ML, Sarr MG, Somers VK, et al. Effect of bariatric surgery on cardiometabolic risk in elderly patients: A population-based study. Geriatr Gerontol Int. 2016 May;16(5):618-24.

19 Susmallian S, Raziel A, Barnea R, Paran H. Bariatric surgery in older adults: should there be an age limit? Medicine (Baltimore). 2019 Jan;98(3):e13824-13824.

20 Nor Hanipah Z, Punchai S, Karas LA, Szomstein S, Rosenthal RJ, Brethauer SA, et al. The Outcome of Bariatric Surgery in Patients Aged 75 years and Older. Obes Surg. 2018 Jun;28(6): 1498-503. 